\title{
Prevalence and Factors Associated with Immediate Postnatal Care Utilization in Ethiopia: Analysis of Ethiopian Demographic Health Survey 2016
}

This article was published in the following Dove Press journal: International Journal of Women's Health

\author{
Berhan Tsegaye $\mathbb{D}^{\prime}$ \\ Belay Amare' \\ Mulu Reda ${ }^{2}$ \\ 'Hawassa University College of Medicine \\ and Health Science, Department of \\ Midwifery, Hawassa, Ethiopia; ${ }^{2}$ Hawassa \\ University College of Natural and \\ Computational Science, Department \\ Statistics, Hawassa, Ethiopia
}

Background: Maternal mortality is unacceptably high in Ethiopia. Most maternal complications are preventable using immediate postnatal care. However, it is not utilized effectively. Hence, this study can assist in formulation of national policies to increase use of immediate postnatal care in Ethiopia.

Objective: To assess the prevalence and factors associated with immediate postnatal care utilization in Ethiopia, in 2016.

Methods: Secondary data analysis was done on Ethiopian Demographic Health Survey 2016 data, in a stratified, two-stage, and cluster sampling study. This analysis was restricted to postnatal women who had given birth at least once in the five years before the survey. Chisquare test of statistics was performed to identify factors associated with immediate postnatal care service uptake. Bi-variable and multi-variable logistic regression analyses were carried out to identify factors associated with immediate postnatal care utilization. Odds ratio with $95 \%$ confidence level was computed and P-value $<0.05$ was considered as statistically significant in the multivariable logistic regression.

Results: The overall level of immediate postnatal care service utilization was $6.3 \%$ in Ethiopia. Urban setting ( $\mathrm{AOR}=2.3,95 \% \mathrm{CI}, 1.9,2.9)$, higher education status $(\mathrm{AOR}=1.6$, $95 \% \mathrm{CI}, 1.3,2.0)$, secondary education status $(\mathrm{AOR}=2.6,95 \% \mathrm{CI}, 1.9,3.6)$, primary education status $(\mathrm{AOR}=3.1,95 \%$ CI $2.0,4.6)$, always listening to the radio $(\mathrm{AOR}=2.4$, $95 \% \mathrm{CI}, 1.7,3.2)$, being in a richer wealth quintile ( $\mathrm{AOR}=4.2,95 \% \mathrm{CI}, 3.0,5.8)$, being in a middle wealth quintile $(\mathrm{AOR}=2.8,95 \% \mathrm{CI}, 2.0,3.9)$, being in a poorer wealth quintile $(\mathrm{AOR}=1.9,95 \% \mathrm{CI}, 1.3,2.8)$, having fewer than six children $(\mathrm{AOR}=1.3,95 \% \mathrm{CI}, 1.1,2.0)$, and being told about pregnancy complications ( $\mathrm{AOR}=2.2,95 \% \mathrm{CI}, 1.7,2.7)$ were factors positively associated with utlilization of immediate postnatal care.

Conclusion: Prevalence of immediate postnatal care utilization is still low in Ethiopia. Awareness should be created about immediate postnatal care utilization through the efforts of health extension workers. In addition, the Ethiopian government should design strategies to enhance the socio-economic status of women. Beside these, information about postnatal care and its benefit is critical and can be transmitted through mass media.

Keywords: immediate postnatal care, Ethiopian demographic health survey, 2016

\section{Background}

Postnatal care service aims at provision of appropriate care for both women and newborns. Besides, it protects against complications which endanger their lives. ${ }^{1}$ Around 287,000 women die from complications occurring during pregnancy, childbirth and postpartum periods every year in the world. Almost all of these
Correspondence: Belay Amare Hawassa University College of Medicine and Health Science, Department of Midwifery, Hawassa, Ethiopia Tel +251967I36387

Email gideteb60@gmail.com
International Journal of Women's Health 2021:13 257-266 
deathsoccur in sub-Saharan African countries. ${ }^{2}$ Previous studies stated that $50 \%$ of maternal deaths and $40 \%$ of neonatal deaths occur within 24 hours after childbirth. ${ }^{3,4}$ In Ethiopia, the maternal mortality ratio was 401 per 100,000 live births in 2017. The incidence of these deaths decreases with increasing time from birth.,

The World Health Organization (WHO) recommends four standard postnatal care visits: 1, 3, 7-14 and 42 days after birth. ${ }^{7}$ Specifically, the Ethiopian Federal Ministry of Health recommends four postnatal care visits at 6-24 hours, 3 days, 6 days and 42 days. ${ }^{8}$ Based on WHO data, the first 24 hours after birth is the most critical time to diagnose complications and provide suitable interventions. $^{9}$

Postnatal care utilization could prevent the death of 60,000 newborns every year. In Ethiopia, it should be possible to reduce neonatal mortality by $10-27 \%$ through effective postnatal care utilization. ${ }^{10}$

Regardless of its benefit, mothers generally do not visit health institutions following childbirth in Africa. Consequently, the coverage of postnatal care service is one of the lowest among reproductive and child health services. ${ }^{11}$ For example, the Ethiopia Demographic and Health Survey 2005 reported that $95 \%$ of women did not receive postnatal care in the first 2 days after childbirth. ${ }^{12}$ Moreover, postnatal care utilization was only $8 \%$ in Ethiopia in $2011 .{ }^{13}$ In addition, only $34.3 \%$ of women received postnatal care at 6 weeks after delivery. ${ }^{14}$

Previous studies have indicated that multi-layered and interlinked factors affect postnatal care utilization. For example, institutional delivery utilization, marital status, wealth quintile and age were reported as factors associated with postnatal care service utilization. ${ }^{15}$ Place of residence, ethnicity, pregnancy intention, antenatal care visits and place of delivery were reported factors associated with variable postnatal care uptake. ${ }^{16}$ There is also evidence that maternal occupation and pregnancy intention were important predictors of postnatal care utilization. ${ }^{17}$ Besides, maternal education, education of partners, health facility delivery, and a skilled delivery attendant at least one postnatal care visit were among valuable factors associated with postnatal care utilization. ${ }^{18}$

The Ethiopian government target is to reduce the maternal mortality ratio to 70 deaths per 100,000 live births by $2030 .{ }^{19}$ Hence, Ethiopia has applied many different strategies to reduce maternal mortality. Comprehensive postnatal health packages through the health extension program is one of the key approaches among these strategies. Postnatal care is the most useful, but the most neglected maternal health service component to improve the survival of women and their babies. Although previous studies have focused on antenatal and delivery service utilization, information on postnatal care is scarce. There is a paucity of national research on immediate postnatal care. The main aim of this study is to assess the prevalence of immediate postnatal care utilization and associated factors in Ethiopia, in 2016.

\section{Methodology \\ Study Area and Period}

Ethiopia is divided into nine regional states and two city administrations. Each regional state is further divided into zones. Zones are again divided into administrative units called districts. Districts are further subdivided into the lowest administrative units called 'Kebeles'. A primary health-care package includes preventive, promoting, and curative services. Postnatal care is one of the most valuable aspects of primary health care. In Ethiopia, health sector development Plan-I has introduced a four-tier health system for health service delivery. It consists of the following institutions in hierarchy: One health center and five satellite health posts, district hospital, zonal hospital, and specialized hospitals. Postnatal care services are primarily offered in health centers free of charge for pregnant women. According to Federal Ministry of Health recommendations, postnatal care should be conducted by health extension workers through home-to-home visits at 24 hours, 3 days and 7 days after birth. ${ }^{20}$ The data collection period of the Ethiopian Demographic Health Survey was from January 18 to June 27, 2016.

\section{Study Variables}

Immediate postnatal care service utilization was the outcome variable for this study. It is a binary outcome variable. Study participants were asked "Whether they utilized postnatal care or not at least one time in the first 24 hours after birth in the most recent birth". They answered either 'Yes' or "No". These answers were coded as ' 1 ' and ' 0 ' respectively during analysis of this study. The covariates included in this study were grouped into sociodemographic and reproductive factors. Sociodemographic factors were variables such as age, place of residence, educational status, husband's educational status, religion, ethnicity, marital status and wealth quintile of women, and total family size. Reproductive variables 
included in this study were age at first marriage, total number of children, antenatal care visits, place of delivery, current pregnancy status, and own mobile phone. The authors classified and categorized some variables to make them comparable with other studies. For example, age of participants was a continuous variable expressed in completed years. It was classified into three categories as: 15-24, 25-34, and 35-49 years. Furthermore, ethnicity was classified into five classes based on their proportion from largest to lowest in Ethiopia. These included: Amhara, Oromo, Somali, Sidama, and Others. The variable total family size was categorized into two parts: 1-5 persons and 6 and more persons. In addition, age at first pregnancy was classified into two classes based on the Ethiopian legal age for marriage. These included age less than 18 years and 18 and above years.

\section{Operational Definition}

Immediate postnatal care is when participants utilize postnatal care at least once within 24 hours after discharge if participants deliver in a health institution or at home. Wealth index was constructed using principal components analysis on household asset data. Individuals were classified into five wealth quintiles (poorest, poorer, medium, richer, and richest). Variables included in the wealth index were ownership of selected household assets, size of agricultural land, quantity of livestock, and materials used for house construction. ${ }^{21}$

\section{Sample Size and Sampling Procedures}

The 2007 population and housing census, which was conducted by the central statistical agency, was the source of the sampling frame for EDHS 2016. Samples were selected using a stratified, two-stage cluster design. Each Kebele (the smallest administration unit of Ethiopia) was subdivided into enumeration areas (EAs) in the 2007 census. They were convenient for the implementation of the census. Enumeration areas were the sampling units in the first stage. There were 181 households in each EA. Stratified, two-stage cluster sampling technique was applied in EDHS 2016. First, 645 EAs were selected, and allocated proportionally in urban and rural areas based on their total number of EAs in Ethiopia. Consequently, 202 were selected from urban areas, and 443 from rural areas. Second, a fixed number of 28 households per cluster/EA were selected using systematic random sampling. Hence, a total of 18,008 households were selected in the country. From these, 17,067 households were occupied by women of reproductive age. However, effective interviews were conducted over 16,650 households. From these, only 16,583 eligible reproductive age women existed in the selected households. Specifically, only 15,683 study participants gave a full response, resulting in a response rate of $95 \%$. A total of 7590 study participants who had given birth at least once in the five years before the survey were selected, and analyzed for the current study. ${ }^{22}$

\section{Study Design and Population}

Secondary data analysis was conducted on the Ethiopian Demographic Health Survey 2016. The EDHS is a community based survey which is conducted at five-year intervals at a national level. Women who gave birth at least once in the five years before the survey were selected for this secondary analysis. For those respondents who gave birth more than once in the past five years, the most recent birth was taken for the current analysis. Therefore, all women who gave the most recent birth in the past five years before data collection of EDHS 2016, and had come for postnatal checkup within 24 hours were the study population of this study. All women who gave birth at least once from 2011-2016 in Ethiopia were the source population of this study.

\section{Data Collection}

Fieldwork was carried out by 33 field teams, each consisting of 1 team supervisor, 1 field editor, 3 female interviewers and 1 male interviewer. In addition, there were 14 quality controllers for EDHS 2016. The pretest was conducted from October 1-28, 2015, in Bishoftu. The central statistical agency recruited 294 people for the main fieldwork, and they were trained to serve as team supervisors, field editors, interviewers, secondary editors, and reserve interviewers. The DHS Program's standard Demographic and Health Survey questionnaires were adapted to reflect the population and health issues relevant to Ethiopia. Five questionnaires were used for the 2016 EDHS: Household questionnaire, woman's questionnaire, man's questionnaire, biomarker questionnaire, and health facility questionnaire. Further details of sampling, questionnaire and procedure can be found in the publicly available survey sampling. The woman's questionnaire was used to collect information from all eligible women aged 15-49. These information includes: background characteristics, family planning, antenatal, delivery, and postnatal care, breastfeeding, sexually transmitted infections, female genital cutting, fistula, violence against women. 


\section{Data Analysis}

Data were analyzed using SPSS version 22 software. First, we selected, re-categorized, and coded important variables for this analysis in the current study. We made them comparable across studies throughout countries. In this analysis, we followed a series of steps. Step 1, we applied sample weighting to compensate for unequal probability of selection among geographic strata. Ideally, both bias and variance should be minimized in a complex survey. Weighting variable was created by dividing the individual woman variable (V005) by $1,000,000$. Hence, prevalence of immediate postnatal care utilization was calculated after weighting the data.

Stratification and clustering were used to compute standard error. We created a plan file by using three variables needed to set up complex samples. These include the following variables in the dataset: primary sample unit (021), sample strata (v022), and weighting created in step 1 . Third, we have fixed sampling with replacement as estimator assumption. Finally, we have analyzed the plan file created in these three steps to identify factors associated with immediate postnatal care utilization. Chi-square test was performed to observe any association between independent variables and an outcome variable. First, we performed binary logistic regression analysis to identify variables associated with immediate postnatal care service utilization. In bi-variable logistic regression analysis, we took variables with P-value less than or equal to 0.05 into multivariable logistic regression analysis to control cofounders. Then, variables which had significant association with antenatal care utilization were identified based on Adjusted Odds Ratio (AOR) and P-value less than 0.05 in the multivariable logistic regression analysis model. Descriptive statistics are presented by the use of texts and tables.

\section{Results}

\section{Socio-Demographic Characteristics}

The majority $(3826 ; 50.4 \%)$ of the study participants were in the age range $25-34$ years. Nearly all $(2884 ; 97.5 \%)$ participants were married. The majority $(2114 ; 71.4 \%)$ of the study participants had no education. From the total respondents more than half $(1741 ; 58.9 \%)$ had no work. The majority of the study participants $(2734 ; 92.4 \%)$ was living in a rural area (Table 1).

Most of the respondents $(6555 ; 91.9 \%)$ were married at the age of $15-24$ years. One of every two study partici-
Table I Socio-Demographic Characteristics of Women Who Utilized Postnatal Care Service in the First 24 Hours for Their Most Recent Birth in $2016(\mathrm{~N}=7590)$

\begin{tabular}{|c|c|c|c|}
\hline Variable & Category & Number & $\begin{array}{l}\text { Percent } \\
\text { (\%) }\end{array}$ \\
\hline Age & $\begin{array}{l}15-24 \text { years } \\
25-34 \text { years } \\
35-49 \text { years }\end{array}$ & $\begin{array}{l}1804 \\
3826 \\
1959\end{array}$ & $\begin{array}{l}23.8 \\
50.4 \\
25.8\end{array}$ \\
\hline Religion & $\begin{array}{l}\text { Orthodox } \\
\text { Catholic } \\
\text { Protestant } \\
\text { Muslim } \\
\text { Traditional } \\
\text { Others }\end{array}$ & $\begin{array}{l}813 \\
29 \\
624 \\
1409 \\
46 \\
38\end{array}$ & $\begin{array}{l}27.5 \\
1 \\
21.1 \\
47.6 \\
1.6 \\
1.3\end{array}$ \\
\hline Marital status & $\begin{array}{l}\text { Married } \\
\text { Single } \\
\text { Divorced } \\
\text { Widowed }\end{array}$ & $\begin{array}{l}2884 \\
10 \\
40 \\
24\end{array}$ & $\begin{array}{l}97.5 \\
0.001 \\
0.005 \\
0.003\end{array}$ \\
\hline Ethnicity & $\begin{array}{l}\text { Amhara } \\
\text { Oromo } \\
\text { Somali } \\
\text { Sidama } \\
\text { Others }\end{array}$ & $\begin{array}{l}436 \\
1386 \\
169 \\
93 \\
874\end{array}$ & $\begin{array}{l}14.7 \\
46.9 \\
5.7 \\
3.1 \\
29.6\end{array}$ \\
\hline Educational status & $\begin{array}{l}\text { No education } \\
\text { Primary } \\
\text { Secondary } \\
\text { Higher }\end{array}$ & $\begin{array}{l}2114 \\
712 \\
89 \\
44\end{array}$ & $\begin{array}{l}71.4 \\
24.1 \\
3 \\
1.5\end{array}$ \\
\hline $\begin{array}{l}\text { Women's } \\
\text { occupation }\end{array}$ & $\begin{array}{l}\text { No work } \\
\text { Government } \\
\text { worker } \\
\text { Daily worker } \\
\text { Others }\end{array}$ & $\begin{array}{l}174 \mid \\
107 \mid \\
121 \\
26\end{array}$ & $\begin{array}{l}58.9 \\
36.2 \\
4.1 \\
0.9\end{array}$ \\
\hline Wealth index & $\begin{array}{l}\text { Poorer } \\
\text { Poorest } \\
\text { Middle } \\
\text { Richer } \\
\text { Richest }\end{array}$ & $\begin{array}{l}842 \\
738 \\
584 \\
499 \\
295\end{array}$ & $\begin{array}{l}28.5 \\
24.9 \\
19.8 \\
16.9 \\
10\end{array}$ \\
\hline Total family size & $\begin{array}{l}1-5 \\
6 \text { and above }\end{array}$ & $\begin{array}{l}1107 \\
1852\end{array}$ & $\begin{array}{l}37.4 \\
62.6\end{array}$ \\
\hline Residence & $\begin{array}{l}\text { Urban } \\
\text { Rural }\end{array}$ & $\begin{array}{l}224 \\
2734\end{array}$ & $\begin{array}{l}7.6 \\
92.4\end{array}$ \\
\hline $\begin{array}{l}\text { Husband's } \\
\text { education }\end{array}$ & $\begin{array}{l}\text { No education } \\
\text { Primary education } \\
\text { Secondary } \\
\text { education } \\
\text { Tertiary and above }\end{array}$ & $\begin{array}{l}3346 \\
2731 \\
613 \\
419\end{array}$ & $\begin{array}{l}44.1 \\
36 \\
8.1 \\
5.9\end{array}$ \\
\hline
\end{tabular}


pants had five and above children. More than half (4771; $62.9 \%$ ) of the respondents had antenatal follow-up in the last childbirth. Most (90.9\%) of the study participants were not pregnant at the time of interview. The majority (5491; $72.3 \%$ ) of the study participants did not listen to the radio at all. Most of the health providers $(175 ; 36.7 \%)$ who provided immediate postnatal care were nurses. The second most prevalent health professional who provided postnatal checkup was health extension workers (157; 32.9\%) (Table 2).

\section{Prevalence of Immediate Postnatal Care}

Data from a total of 7590 participants were extracted and analyzed. The response rate of this study was found to be

Table 2 Reproductive Health Characteristics of Women Who Access Postnatal Care in 2019 ( N=7590)

\begin{tabular}{|c|c|c|c|}
\hline Variable & Category & Number & Percent \\
\hline \multirow{3}{*}{ Age at first mirage } & 15-24 years & 6555 & 91.9 \\
\hline & $25-34$ years & 565 & 7.9 \\
\hline & $34-49$ years & 10 & 0.14 \\
\hline \multirow[t]{3}{*}{ Total number of births } & One to two & 554 & 18.7 \\
\hline & Three to four & 931 & 31.5 \\
\hline & Five and above & 1474 & 49.0 \\
\hline \multirow{2}{*}{$\begin{array}{l}\text { Antenatal care for last } \\
\text { birth }\end{array}$} & No & 2818 & 37.1 \\
\hline & Yes & 4771 & 62.9 \\
\hline \multirow{3}{*}{$\begin{array}{l}\text { Number of antenatal } \\
\text { care visit }\end{array}$} & One to two visit & 942 & 19.7 \\
\hline & $\begin{array}{l}\text { Three to four } \\
\text { visit }\end{array}$ & 2594 & 54.3 \\
\hline & $\begin{array}{l}\text { Five and four } \\
\text { visit }\end{array}$ & 1236 & 25.9 \\
\hline \multirow[t]{2}{*}{ Current pregnancy } & Yes & 268 & 9.1 \\
\hline & No & 2690 & 90.9 \\
\hline \multirow{2}{*}{$\begin{array}{l}\text { Place of delivery of the } \\
\text { last child }\end{array}$} & Home & 5181 & 68.3 \\
\hline & Health institution & 2409 & 31.7 \\
\hline \multirow{3}{*}{$\begin{array}{l}\text { Frequency of listening } \\
\text { radio }\end{array}$} & Not at all & 5491 & 72.3 \\
\hline & $\begin{array}{l}\text { Less than one } \\
\text { per week }\end{array}$ & 1030 & 13.6 \\
\hline & $\begin{array}{l}\text { At least one per } \\
\text { week }\end{array}$ & 1069 & 14.1 \\
\hline \multirow[t]{2}{*}{ Own mobile } & No & 6217 & 81.9 \\
\hline & Yes & 1373 & 18.1 \\
\hline
\end{tabular}

$100 \%$. Prevalence of immediate postnatal care utilization was $478(6.3 \%)$ in this study.

\section{Cross Tabulation of Factors Associated with Immediate Postnatal Care Utilization}

As shown in eight variables were associated with immediate postnatal care utilization using chi-square test statistics. Variables with $\mathrm{P}$ value less than 0.05 were reported to have a significant association with outcome variables and were taken to bi-variable logistic regression analysis. All of these eight variables also showed significant association in bi-variable logistic regression. P-value of less than 0.25 was considered as a cutoff point for significantly associated variables in the bi-variable logistic regression analysis (Table 3 ).

\section{Factors Associated with Immediate Postnatal Care}

There were eight factors significantly associated with immediate postnatal care utilization in this study. But, only six factors were identified as being statistically significant in the multivariable logistic regression analysis. Women who lived in urban areas were 2.3 times more likely to utilize postpartum care than their counterparts (AOR=2.3, 95\% CI, 1.9, 2.9). Compared with non-educated women, women with higher education status were 1.6 times more likely to use the postnatal care service $(\mathrm{AOR}=1.6,95 \% \mathrm{CI}, 1.3,2.0)$. Women with secondary education status were $2.6(\mathrm{AOR}=2.6,95 \%$ CI, 1.9, 3.6), and women with primary education were 3.1 times $(2.0-4.6)$ more likely to utilize postnatal care than uneducated women. Women who always listen to the radio were 2.4 times more likely than their counterparts $(\mathrm{AOR}=2.4,95 \% \mathrm{CI}, 1.7,3.2)$ to utilize the postnatal care service. Women in richer wealth quintile were 4.2 times (AOR=4.2, 95\% CI, 3.0, 5.8), women in middle wealth quintile were 2.8 times $(\mathrm{AOR}=2.8$, $95 \% \mathrm{CI}, 2.0,3.99$ ), women in poorer wealth quintile were $1.9(\mathrm{AOR}=1.9,95 \% \mathrm{CI}, 1.3,2.8)$ times more likely than the poorest women to utilize postnatal care. Women who had less than six children were 1.3 times more likely to utilize postnatal care than their counterparts $(\mathrm{AOR}=1.3,95 \% \mathrm{CI}, 1.1,2.0)$. This analysis also reveals that women who were told about 
Table 3 Cross Tabulation of Factors Associated with Immediate Postnatal Care in Ethiopia in 2016, EDHS (N=7590)

\begin{tabular}{|c|c|c|c|c|c|}
\hline \multirow[t]{2}{*}{ Variables } & \multirow[t]{2}{*}{ Value } & \multicolumn{2}{|c|}{ Immediate Postnatal Care Utilization } & \multirow[t]{2}{*}{ Pearson Chi-Square Value } & \multirow[t]{2}{*}{ P-value } \\
\hline & & Yes & No & & \\
\hline Place of residence & $\begin{array}{l}\text { Urban } \\
\text { Rural }\end{array}$ & $\begin{array}{l}117 \\
361\end{array}$ & $\begin{array}{l}852 \\
6260\end{array}$ & 62.81 & 0.000 \\
\hline Respondent's educational status & $\begin{array}{l}\text { Higher } \\
\text { Secondary } \\
\text { Primary } \\
\text { No education }\end{array}$ & $\begin{array}{l}231 \\
166 \\
51 \\
31\end{array}$ & $\begin{array}{l}4560 \\
1984 \\
370 \\
198\end{array}$ & 67.73 & 0.000 \\
\hline Frequency of listening to radio & $\begin{array}{l}\text { Almost always } \\
\text { Once per week } \\
\text { Not at all }\end{array}$ & $\begin{array}{l}414 \\
53 \\
10\end{array}$ & $\begin{array}{l}6636 \\
352 \\
125\end{array}$ & 53 & 0.000 \\
\hline Wealth index combined & $\begin{array}{l}\text { Richest } \\
\text { Poorer } \\
\text { Middle } \\
\text { Richer } \\
\text { Poorest }\end{array}$ & $\begin{array}{l}51 \\
64 \\
94 \\
118 \\
150\end{array}$ & $\begin{array}{l}1601 \\
1590 \\
1494 \\
1308 \\
1119\end{array}$ & 47.45 & 0.000 \\
\hline Number of children & $\begin{array}{l}\text { I-5 children } \\
6 \text { and above }\end{array}$ & $\begin{array}{l}264 \\
213\end{array}$ & $\begin{array}{l}3372 \\
3740\end{array}$ & 8.31 & 0.004 \\
\hline Told about pregnancy complication & $\begin{array}{l}\text { Yes } \\
\text { No }\end{array}$ & $\begin{array}{l}153 \\
257\end{array}$ & $\begin{array}{l}2473 \\
1889\end{array}$ & 56.86 & 0.000 \\
\hline Husband education & $\begin{array}{l}\text { No education } \\
\text { Primary } \\
\text { Secondary } \\
\text { Tertiary }\end{array}$ & $\begin{array}{l}3182 \\
2557 \\
555 \\
374\end{array}$ & $\begin{array}{l}163 \\
180 \\
67 \\
45\end{array}$ & & \\
\hline Own mobile telephone & $\begin{array}{l}\text { No } \\
\text { Yes }\end{array}$ & $\begin{array}{l}318 \\
159\end{array}$ & $\begin{array}{l}5898 \\
1214\end{array}$ & 79.9 & 0.000 \\
\hline
\end{tabular}

pregnancy complications were 2.2 times more likely to use postnatal care than their counterparts $(\mathrm{AOR}=2.2$, 95\% CI, 1.7, 2.7) (Table 4).

\section{Discussion}

We have tried to assess immediate postnatal care utilization in Ethiopia using data from the Ethiopian Demographic Health Survey 2016. Although previous studies were conducted in Ethiopia, they failed to address immediate postnatal care uptake at a national level. Most maternal deaths that are occur are due to heavy bleeding within 24 hours of childbirth. Hence, immediate postnatal care utilization is the critical period in the lives of women and their children. Furthermore, this study had a number of unique characteristics: the proportion of immediate newborn care at community level, EDHS data use a standard measurement tool, and the study utilized an adequate sample size.
Prevalence of immediate postnatal care utilization was found to be $6.3 \%$ in this study. This finding is lower than those of studies conducted in some other African countries: Tanzania (10.4\%), Rwanda (12.8\%), ${ }^{15}$ and Nigeria $(37 \%) .{ }^{23}$ The possible reason for this difference might be due to low awareness level of immediate postnatal care availability among women in this study. ${ }^{24}$ It might be also be due to widespread cultural and spiritual taboos, and misinformed beliefs in Ethiopia. For instance, that postpartum women should not go out of home alone as they could be affected by evil spirits. Previous research showed that women might not utilize postnatal care due to social and traditional perceptions. ${ }^{25,26}$ Lastly, it is apparent that the socio-demographic level of study participants in Ethiopia and the study participants in countries mentioned above are be comparable.

In this study, postnatal care utilization is highly associated with socio-demographic factors and reproductive 
Table 4 Factors Associated with Postnatal Care Service Utilization from Backward Stepwise (Wald) Analysis of Multi-Variable Logistic Regression Among Study Population ( $\mathrm{N}=7590)$

\begin{tabular}{|c|c|c|c|c|c|}
\hline \multirow[t]{2}{*}{ Variables } & \multirow[t]{2}{*}{ Value } & \multicolumn{2}{|c|}{ PNC Uptake } & \multirow[t]{2}{*}{$\operatorname{AOR}(95 \% \mathrm{Cl})$} & \multirow[t]{2}{*}{ P-value } \\
\hline & & Yes & No & & \\
\hline Place of residence & $\begin{array}{l}\text { Urban } \\
\text { Rural }\end{array}$ & $\begin{array}{l}117 \\
361\end{array}$ & $\begin{array}{l}852 \\
6260\end{array}$ & $\begin{array}{l}2.3(1.9,2.9)^{* *} \\
1\end{array}$ & 0.000 \\
\hline Respondent's educational status & $\begin{array}{l}\text { Higher } \\
\text { Secondary } \\
\text { Primary } \\
\text { No education }\end{array}$ & $\begin{array}{l}231 \\
166 \\
51 \\
31\end{array}$ & $\begin{array}{l}4560 \\
1984 \\
370 \\
198\end{array}$ & $\begin{array}{l}\text { I.6(I.3,2.0)** } \\
2.6(I .9,3.6)^{* *} \\
3 . I(2.0,4.6)^{* *} \\
\text { I }\end{array}$ & 0.000 \\
\hline Frequency of listening to radio & $\begin{array}{l}\text { Almost always } \\
\text { Once per week } \\
\text { Not at all }\end{array}$ & $\begin{array}{l}414 \\
53 \\
10\end{array}$ & $\begin{array}{l}6636 \\
352 \\
125\end{array}$ & $\begin{array}{l}2.4(1.7,3.2)^{* *} \\
\text { I.2(0.6,2.4) } \\
\text { I }\end{array}$ & 0.000 \\
\hline Wealth index combined & $\begin{array}{l}\text { Richest } \\
\text { Poorer } \\
\text { Middle } \\
\text { Richer } \\
\text { Poorest }\end{array}$ & $\begin{array}{l}51 \\
64 \\
94 \\
118 \\
150\end{array}$ & $\begin{array}{l}1601 \\
1590 \\
1494 \\
1308 \\
1119\end{array}$ & $\begin{array}{l}\text { I.2 }(0.8,1.8) \\
1.9(1.3,2.8)^{* *} \\
2.8(2.0,3.9)^{* *} \\
4.2(3.0,5.8)^{* *} \\
1\end{array}$ & 0.000 \\
\hline Number of children & $\begin{array}{l}\text { I-5 children } \\
6 \text { and above }\end{array}$ & $\begin{array}{l}264 \\
213\end{array}$ & $\begin{array}{l}3372 \\
3740\end{array}$ & $\begin{array}{l}\mathrm{I} .3(\mathrm{I} . \mathrm{I}, 2.0)^{* *} \\
\mathrm{I}\end{array}$ & 0.005 \\
\hline Told about pregnancy complications & $\begin{array}{l}\text { Yes } \\
\text { No }\end{array}$ & $\begin{array}{l}153 \\
257\end{array}$ & $\begin{array}{l}2473 \\
1889\end{array}$ & $\begin{array}{l}2.2(1.7-2.7)^{* *} \\
\text { । }\end{array}$ & 0.000 \\
\hline
\end{tabular}

Notes: I, References group; **P-value less than 0.05 .

Abbreviations: AOR, adjusted odds ratio; PNC, postnatal care.

factors. These were: Educational status, place of residence, listening to the radio, wealth quintile, number of children, and being told about pregnancy complications. Specifically, urban women were more likely to utilize immediate postnatal care than their counterparts. This finding is consistent with a study conducted in Loma district, South Ethiopia. ${ }^{27}$ This might be due to the fact that study participants in urban areas have more access to information about the benefits of immediate postnatal care service utilization than their counterparts. A previous study also showed that the extent of women's awareness about postnatal care availability determined postnatal care service uptake. ${ }^{28}$ Moreover, urban dwellers could access immediate postnatal care services more easily than their counterparts. In addition, cultural malpractice and misconceptions are more prevalent among rural communities which can hinder postnatal care utilization. More than $80 \%$ of Ethiopian women are believed to live in rural areas, from which the study participants were drawn for this study. Women are affected by several reasons mentioned above and they could not use immediate postnatal care. Most previous studies were conducted on health institutions and relatively urban areas which cannot capture reliable estimates of utilization of immediate postnatal care.

Women with primary education status had higher odds of immediate postnatal care utilization than non-educated women, and women with secondary education status were more likely to utilize immediate postnatal care than noneducated women. Women with higher educational status were far more likely to use an immediate postnatal care service than non-educated women. This finding is in line with finding of studies conducted in Ethiopia, Indonesia, Uganda, and India. ${ }^{29-31}$ This consistency could be explained by the fact that education gives women skills in informed decision making, which in turn increases their health-seeking behavior. ${ }^{32,33}$ Furthermore, education can give economic independence and political participation through which women can attain gender equality. ${ }^{34}$ As overall women's development is improved, they start to use health services including postnatal care. Furthermore, education is the key for health service utilization through reading of health messages. Most Ethiopian women who live in rural areas marry young, and they are uneducated. 
Women who listened to the radio at least once per week utilized immediate postnatal care services more than women who did not listen at all. This result is consistent with studies in Adwa, Southern Ethiopia, Jabitena Amhara, Kenya and Nepal. ${ }^{18,35-38}$ It is clear that listening to the radio can increase the chance of getting information about immediate postnatal care utilization. So, study participants can anticipate health risks and benefits of having immediate postnatal care in the first 24 hours. ${ }^{39,40}$ This could indicate media had little role on the improvement of immediate postnatal care. Specifically, the radio had higher impact on health messages; however, the radio had little or no airtime for messages about danger signs after delivery, thus leaving women unaware and with less uptake of the service. Women in the richer wealth quintile were more likely to utilize immediate postnatal care than women in the poorest wealth quintile. Women in the middle wealth quintile were more likely to utilize immediate postnatal care than women in the poorest wealth quintile, and women in the poorer wealth quintile were more likely to use immediate postnatal care than women in the poorest wealth quintile. This finding is consistent with a study conducted in Rwanda. ${ }^{15}$ The expected explanation could be that wealth is necessary for direct and indirect costs related with immediate postnatal care utilization, and to have different assets as sources of information. Previous evidence showed that low wealth in a household leads to low maternal health service utilization. ${ }^{41}$ Women who have six or fewer children were more likely to utilize an immediate postnatal care service than their counterparts. This was in line with another study done in Ethiopia. ${ }^{42}$ The possible reason might be that women with fewer children had little experience about pregnancy and childbirth. So, they had less confidence in their health status which in turn increases immediate postnatal care utilization. Moreover, women who had few children could get enough income and time to care for their babies than their counterparts. This is supported by the findings of previous studies. ${ }^{43,44}$ Study participants who were told about pregnancy complications used immediate postnatal care services more than their counterparts. This study finding is in line with a previous study done in Goba Woreda, in Ethiopia. ${ }^{45}$ The possible explanation might be due to the fact that awareness of maternal complications is an important factor in motivating women and their families to attend a health-care service at the earliest time.

\section{Limitation and Strength}

The current study has a number of strengths. We used national survey data and a relatively large sample size with a high response rate (95\%). It utilized internationally validated and nationally adapted surveys. Therefore, the current findings are generalizable to the entire country. This is more likely to yield accurate estimates. In addition, this is the first study to report the prevalence and factors associated with utilization of immediate postnatal care in Ethiopia. Nevertheless, the current study has several limitations. As the survey asked information retrospectively, this may have yielded some recall bias. Nevertheless, this bias is not considered problematic since this study included only women giving birth within five years preceding the survey. Moreover, this secondary data analysis of Ethiopian Demographic and Health Survey could not provide some variables.

\section{Conclusion and Public Health Implication}

The overall prevalence of immediate postnatal care is very low in this study. Living in rural areas, being uneducated, being lowest in wealth quintile, living in large families, not listening to the radio, and lack of information about pregnancy complications were factors affecting immediate postnatal care utilization in Ethiopia in 2016. Information dissemination should be intensified by stakeholders about immediate postnatal care utilization. The government should work to improve the socio-economic status of women. Moreover, family planning programs should work for accessible and high-quality family planning services. Finally, health extension workers should strongly enhance awareness among rural women in Ethiopia and link women with health institutions in case of postnatal complications.

\section{Abbreviations}

WHO, World Health Organization; PNC, postnatal care; CI, confidence interval; DHS, demographic and health surveys; COR, crude odds ratios; SNNPRs, Southern Nation Nationality and People Regional State; EAs, enumeration areas; CSA, Central Statistical Agency.

\section{Data Sharing Statement}

Permission to access database was obtained. Database was available at https://dhsprogram.com. 


\section{Ethics Approval and Consent to Participate}

We registered and requested data from DHS on-line archive. We received an approval to download identified DHS data files.

\section{Acknowledgments}

We would like to acknowledge 'Measure DHS' for granting permission to use the Demographic and Health Survey data in this secondary analysis.

\section{Author Contributions}

All authors made a significant contribution to this study. They participated in study conception, design, execution, analysis, and interpretation effectively. Moreover, they took part in drafting, revising, or critically reviewing the first draft. Furthermore, they gave their approval for the final version to be published.

\section{Funding}

There was no any funding or sponsoring organization for this paper.

\section{Disclosure}

All authors declare that they had no competing interest.

\section{References}

1. Lawn J, Kerber K Opportunities for Africas newborns: practical data policy and programmatic support for newborn care in Africa. 2006.

2. Organization WH. Trend in maternal mortality: 1990 to 2010: WHO, UNICEF, UNFPA and The World Bank estimates; 2012.

3. Nabukera SK, Witte K, Muchunguzi C, et al. Use of postpartum health services in rural Uganda: knowledge, attitudes and barriers. $J$ Community Health. 2006;31(2):84-93. doi:10.1007/s10900-0059003-3

4. Matthews M, Severin V, Jelka Z. WHO Technical Consultation on Postpartum and Postnatal Care. Geneva: World Health Organization; 2010.

5. Organization WH. Trends in maternal mortality: 1990-2015: estimates from WHO, UNICEF, UNFPA, World Bank Group and the United Nations Population Division: executive summary: World Health Organization; 2015.

6. Bwalya BB, Mulenga MC, Mulenga JN. Factors associated with postnatal care for newborns in Zambia: analysis of the 2013-14 Zambia demographic and health survey. BMC Pregnancy Childbirth. 2017;17 (1):1-13. doi:10.1186/s12884-017-1612-1

7. Organization WH. WHO recommendations on postnatal care of the mother and newborn: World Health Organization; 2014.

8. Ethiopia FDRo, Health Mo. Management protocol on selected obstetrics topics; 2010.

9. Organization WH. WHO technical consultation on postpartum and postnatal care: World Health Organization; 2010.
10. Federal Democratic Republic of Ethiopia Ministry of Health. Postnatal Care Module: Ethiopian Federal Ministry of Health. Available from: https://www.open.edu/openlearncreate/mod/oucon tent/view.php?id=332. Accessed January 25,2019.

11. Organization WH. Make every mother and child count: World Health Day, 7 April 2005: a toolkit for organizers of activities: World Health Organization; 2005.

12. Demographic E. Health Survey: Addis Ababa, Ethiopia and Calverton. Maryland, USA: Central Statistical Agency and ORC Macro; 2006.

13. Demographic CE. Health Survey 2011 Addis Ababa, Ethiopia and Calverton. Maryland: Central Statistical Agency and ICF International; 2011.

14. Addis Ababa E; Federal Democratic Republic of Ethiopia. Ministry of Health. Health and health related indicators. Policy plan directorate monitoring and evaluation case team. 2008;9:12.

15. Rwabufigiri BN, Mukamurigo J, Thomson DR, Hedt-Gautier BL, Semasaka JPS. Factors associated with postnatal care utilisation in Rwanda: a secondary analysis of 2010 Demographic and Health Survey data. BMC Pregnancy Childbirth. 2016;16(1):122. doi:10.1186/s12884-016-0913-0

16. Kanté AM, Chung CE, Larsen AM, Exavery A, Tani K, Phillips JF. Factors associated with compliance with the recommended frequency of postnatal care services in three rural districts of Tanzania. Pregnancy Childbirth. 2015;15(1):1.

17. Wudineh KG, Nigusie AA, Gesese SS, Tesu AA, Beyene FY. Postnatal care service utilization and associated factors among women who gave birth in Debretabour town, North West Ethiopia: a community-based cross-sectional study. BMC Pregnancy Childbirth. 2018;18(1):508. doi:10.1186/s12884-018-2138-x

18. Khanal V, Adhikari M, Karkee R, Gavidia T. Factors associated with the utilisation of postnatal care services among the mothers of Nepal: analysis of Nepal demographic and health survey 2011. BMC Women's Health. 2014;14(1):19. doi:10.1186/1472-6874-14-19

19. Lim SS, Allen K, Bhutta ZA, et al. Measuring the health-related sustainable development goals in 188 countries: a baseline analysis from the Global Burden of Disease Study 2015. Lancet. 2016;388 (10053):1813-1850.

20. Oladapo OT, Osiberu MO. Do sociodemographic characteristics of pregnant women determine their perception of antenatal care quality? Matern Child Health J. 2009;13(4):505-511. doi:10.1007/s10995-008-0389-2

21. Rutstein SO, Staveteig S. Making the Demographic and Health Surveys Wealth Index Comparable. Vol. 9. Rockville, MD: ICF International; 2014.

22. Central Statistical Agency Addis Ababa E. Demographic and health survey 2016 key indicators report; 2016:3-4.

23. Somefun OD, Ibisomi L. Determinants of postnatal care non-utilization among women in Nigeria. BMC Res Notes. 2016;9 (1):21. doi:10.1186/s13104-015-1823-3

24. Sharma A, Thakur PS, Kasar PK, Tiwari R, Sharma R. Utilization of postnatal care in tribal area of Madhya Pradesh: a community based cross sectional study. Int $J$ Med Sci Public Health. 2014;3 (10):1266-1272. doi:10.5455/ijmsph.2014.110720142

25. Lama S, Krishna AKI. Barriers in utilization of maternal health care services: perceptions of rural women in Eastern Nepal. Kathmandu Univ Med J. 2014;12(4):253-258. doi:10.3126/kumj. v12i4.13730

26. Serizawa A, Ito K, Algaddal A, Eltaybe R. Cultural perceptions and health behaviors related to safe motherhood among village women in Eastern Sudan: ethnographic study. Int J Nurs Stud. 2014;51 (4):572-581. doi:10.1016/j.ijnurstu.2013.08.007

27. Yarinbab TE, Tona W. Postnatal care utilization and its determinants in Loma District, Southwest Ethiopia: a community based cross sectional study. Women's Health Gynecol. 2018;5(103):1-8. 
28. Paudel DP, Nilgar B, Bhandankar M. Determinants of postnatal maternity care service utilization in rural Belgaum of Karnataka, India: a community based cross-sectional study. Int J Med Public Health. 2014;4(1). doi:10.4103/2230-8598.127167

29. Uppadhaya SK, Bhansali S, Sivodia SK, Agrawal N, Garg K, Singh M. Utilization of postnatal care services in rural area of Western Rajasthan, India. Ntl J Community Med. 2016;7(7):569-572.

30. Aminah K Factors determining the utilization of postpartum care services in Uganda. Ugandan Demographic and Health Survey (UDHS); 2006.

31. Nayan SK, Begum N, Abid MR, et al. Utilization of postnatal care services among the rural women in Bangladesh. North Int Med Coll J. 2017;8(2):208-212. doi:10.3329/nimcj.v8i2.32551

32. Kritz MM, Makinwa-Adebusoye P Determinants of women's decision-making authority in Nigeria: the ethnic dimension. In: Sociological Forum. Kluwer Academic Publishers-Plenum Publishers; 1999.

33. Sultana A. Factors effect on women autonomy and decision-making power within the household in rural communities. J Appl Sci Res. 2011;7(1):18-22.

34. Goetz AM Women's education and political participation. Paper commissioned for the ECFA Global Monitoring Report. 2003:4.

35. $\mathrm{Cl} \mathrm{O}$. Assessment of utilization of postpartum care services among women in Webuye West, Bungoma County, Kenya, Kenyatta University; 2017.

36. Berhe H, Tilahun W, Aregay A, Bruh G, Gebremedhin hgh. utilization and associated factors of postnatal care in adwa town, tigray, ethiopia- a cross sectional study, 2013.

37. Abebo TA, Tesfaye DJ. Postnatal care utilization and associated factors among women of reproductive age Group in Halaba Kulito Town, Southern Ethiopia. Arch Public Health. 2018;76(1):1-10. doi:10.1186/s13690-017-0251-3
38. Workineh YG, Hailu DA. Factors affecting utilization of postnatal care service in Jabitena district, Amhara region, Ethiopia. Sci J Public Health. 2014;23:169-176. doi:10.11648/j.sjph.20140203.15

39. Rahman KM. Determinants of maternal health care utilization in Bangladesh. Res J Appl Sci. 2009;4(3):113-119.

40. Regassa N. Antenatal and postnatal care service utilization in southern Ethiopia: a population-based study. Afr Health Sci. 2011;11 (3):390-397.

41. Mahabub-Ul-Anwar RU, Talukder N. Inequalities in maternal health care utilization in rural Bangladesh. Int $Q$ Community Health Educ. 2008;27(4):281-297. doi:10.2190/IQ.27.4.b

42. Kifle D, Azale T, Gelaw YA, Melsew YA. Maternal health care service seeking behaviors and associated factors among women in rural Haramaya District, Eastern Ethiopia: a triangulated community-based cross-sectional study. Reprod Health. 2017;14 (1):6. doi:10.1186/s12978-016-0270-5

43. Ononokpono DN, Odimegwu CO. Determinants of maternal health care utilization in Nigeria: a multilevel approach. Pan Afr Med J. 2014;17(Suppl 1). doi:10.11604/pamj.supp.2014.17.1.3596

44. Gabrysch S, Campbell OM. Still too far to walk: literature review of the determinants of delivery service use. BMC Pregnancy Childbirth. 2009;9(1):34. doi:10.1186/1471-2393-9-34

45. Odo D, Shifti D. Institutional delivery service utilization and associated factors among child bearing age women in Goba Woreda, Ethiopia. J Gynecol Obstet. 2014;2(4):63-70. doi:10.11648/j. jgo.20140204.14

\section{Publish your work in this journal}

The International Journal of Women's Health is an international, peerreviewed open-access journal publishing original research, reports, editorials, reviews and commentaries on all aspects of women's healthcare including gynecology, obstetrics, and breast cancer. The manuscript management system is completely online and includes a very quick and fair peer-review system, which is all easy to use. Visit http://www.dovepress.com/testimonials.php to read real quotes from published authors. 